\title{
Comment: "Perspectives on water flow and the interpreta- tions of FLIR images" J. Range Manage. 55:106-111 2002
}

\author{
ROBERT L. BESCHTA ${ }^{1}$, BRUCE A. MCINTOSH ${ }^{2}$, and CHRISTIAN E. TORGERSEN ${ }^{3}$
}

\begin{abstract}
${ }^{\prime}$ Professor Emeritus of Forest Hydrology, Dept. of Forest Eng., Oregon State Univ., Corvallis, Ore. 97331, ${ }^{2}$ Courtesy Assistant Professor, Dept. of Fisheries and Wildlife, Oregon State Univ., Corvallis, Ore. 97331, and ${ }^{3}$ Research Biol., Forest and Rangeland Ecosystem Science Center, U.S. Geological Survey, Corvallis, Ore. 97331.
\end{abstract}

\begin{abstract}
Science is increasingly being called upon as a fundamental element in managing the nation's natural resources for the public good. Thus, we were quite surprised to see a recent feature article in the Journal of Range Management by Larson et al. (2002) which provided several scientifically unsubstantiated and potentially controversial conclusions. Their conclusions not only misrepresent current understandings of thermal remote sensing but generally disregard a wealth of peer-reviewed research. Given that range managers and researchers unfamiliar with the capabilities of thermal remote sensing and heat transfer processes in streams might simply accept the conclusions of Larson et al. (2002) without question, we feel that additional discussion is needed.
\end{abstract}

Before addressing issues of concern, we are encouraged that Larson et al. (2002) recognize that salmon recovery in the Pacific Northwest is an important natural resources management issue and a major concern in watersheds where high summertime stream temperatures occur. Improving instream habitat in general and reducing abnormally high stream temperatures specifically are important regional issues that need to be addressed to help insure the recovery and sustainability of depressed salmonid populations (Beschta 1997). A broad base of literature indicates that where high summertime temperatures are common, a number of adverse effects to salmonids and other aquatic organisms are possible (for an extensive review of the literature see McCullough et al. 2001).

In the discussion that follows, we address five major concerns raised by the Larson et al. (2002) article:

\section{(1) The scientific credibility of thermal remote sensing}

\section{for stream temperature assessment}

Thermal infrared remote sensing is a well-established method for measuring water temperature, particularly in ocean and lake environments (Lillesand and Kiefer 1994). There is also an increasing body of literature that provides the background necessary to apply remote sensing techniques for mapping temperature patterns in streams (Atwell et al. 1971, Belknap and Naiman 1998, Kay et al. 2001).

Researchers at Oregon State University, in cooperation with the Oregon Environmental Protection Agency and the U.S. Army Corps of Engineers, have been investigating the application of

\footnotetext{
Acknowledgments

We are indebted to the helpful suggestions and comments provided by George W. Brown III, Sherri L. Johnson, and a third reviewer. However, any interpretations and conclusions represented above obviously remain those of the authors.

Manuscript accepted 20 Oct. 2002.
}

FLIR imagery for stream temperature assessment since 1994 (Norton et al. 1996). In an accuracy assessment, 67 ground-truth measurements were compared with concurrently sensed FLIR temperatures. Data from five different streams and four different years indicated a near perfect linear relationship $\left(r^{2}=0.99\right)$ and an average difference of $0.3^{\circ} \mathrm{C}$ (Torgersen et al. 2001). The analysis demonstrated that FLIR technology provides accurate measurements of stream temperature in a variety of geographic and environmental conditions.

Torgersen et al. (2001) also confirmed that FLIR surveys were effective for mapping spatial patterns of water temperature by comparing longitudinal temperature profiles produced from the analysis of FLIR imagery to that measured by instream sensors. The authors concluded that thermal stratification has a negligible effect on the accuracy of remote measurements under most stream conditions due to turbulent mixing in the water column. However, they also recognized that thermal stratification may develop in side channels, backwaters, floodplain ponds, and other low-velocity habitats, thus complicating image interpretation of unmixed aquatic habitats.

Larson et al. (2002) base much of their criticism over the use FLIR imagery on the interpretation of a very small portion of a single FLIR image in a draft agency report (Fig. 1 [Larson et al. 2002]). The image in question was collected in the late afternoon (16:40) on 22 August 1995 along a reach of the Grande Ronde River in eastern Oregon $\left(45^{\circ} 24.916^{\prime} \mathrm{N}, 117^{\circ} 55.576^{\prime} \mathrm{W}\right)$. Close inspection of the FLIR image and the associated aerial photograph indicate that the relatively cool pixels of concern to Larson et al. (2002) occur near the edge of the stream and represent a microhabitat that might best be described as a small local backwater. Given this situation, it would be reasonable to expect that water in this location is relatively shallow, slow-moving, and not well-mixed relative to that of the mainstream flow. Thus, its temperature regime is likely to behave differently to changing environmental conditions than that of the mainstream.

\section{(2) The use of FLIR imagery by the scientific community}

Traditional methods of measuring stream temperatures using instream data loggers provide data that are temporally continuous but spatially limited. However, spatially continuous data along stream and river reaches are increasingly needed to map thermal conditions at the scale of watersheds to provide better understanding of non-point sources of thermal pollution and mechanisms of human-caused thermal degradation (Poole and Berman 2001). Torgersen et al. (1999 and 2001) and Faux et al. (2001) have found that thermal infrared imagery can be an effective tool for quantifying watershed and reach-scale temperature patterns in 
medium- to large-sized streams and rivers (2nd-order or higher). Integrating spatial imagery (e.g., FLIR imagery) with temporal thermal data from instream data loggers can provide a more spatially and temporally continuous perspective on water temperature patterns within and among stream systems. Contrary to the assertions of Larson et al. (2002), the research community and the Oregon Department of Environmental Quality (ODEQ) are not using FLIR imagery to evaluate microhabitat effects of streamside vegetation on water temperatures.

\section{(3) An energy balance approach to assessing stream cooling}

In an attempt to support their contention that shaded water near the edge of a stream cannot be $\sim 2^{\circ} \mathrm{C}$ cooler than the mainstream water, Larson et al. (2002) provide a mathematical development of how energy loss by conduction might be evaluated. However, understanding changes in water temperature requires consideration of multiple energy transfer processes. An energy balance approach (Sellers 1969) to predicting stream temperature dynamics involves a delineation of the various heat sources and sinks, such as net solar radiation (sr), net longwave radiation (lr), evaporation (ev), convection (co), advection (ad), and bed conduction (bc). Algebraically, the energy balance can be represented as:

$$
\mathbf{Q}=+\mathrm{sr} \pm \mathrm{lr} \pm \mathrm{ev} \pm \mathrm{co} \pm \mathrm{ad} \pm \mathrm{bc}
$$

where $\mathbf{Q}$ represents the total heat energy that is absorbed $(+)$ or released $(-)$ by a stream.

Larson et al. (2002) undertake an extensive mathematical development focused on bed conduction (typically a relatively minor component of the energy balance) to explain why water along the edge of a channel cannot be cooler than the mainstream flow, which is exposed to full sunlight. In the process, they ignore the potential role of other heat transfer components such as absorbed solar radiation (sr), net longwave radiation (lr), and evaporation (ev) that are often of much greater importance.

\section{(4) A field experiment}

Larson et al. (2002) provide the results of a field experiment that was ostensibly designed to prove that stream temperatures cannot differ by $\sim 1-2^{\circ} \mathrm{C}$ over a channel distance of $12 \mathrm{~m}$. Unfortunately, their experiment was not undertaken along the reach of concern (i.e., Fig. 1). Instead, another unspecified stream was selected in the general region of eastern Oregon. Stream temperature measurements were made along an exceptionally short (12-m long) section of channel during several clear days in late summer when the solar angle was $\sim 54^{\circ}$ at noon. The velocity of flow was $0.3 \mathrm{~m} / \mathrm{s}$. Temperature sensors, with a reported accuracy of $+0.2^{\circ} \mathrm{C}$, were placed at a depth of $25 \mathrm{~cm}$, however the depth of water, a critical variable in stream temperature dynamics, was not indicated.

Under clear-sky meteorological conditions typical of eastern Oregon in late summer and with no shading from streamside vegetation or topography, a net solar radiation of approximately 1.27 $\mathrm{cal} / \mathrm{cm}^{2} / \mathrm{min}$ would be available to the stream (assuming a solar angle of $54^{\circ}$ at noon, a latitude of $45^{\circ}$, an elevation of $1000 \mathrm{~m}$, no clouds, and an atmospheric relative humidity of $10 \%$ ) Beschta and Weatherred 1984). These solar inputs during the 40 seconds required for water to flow through the 12-m long reach (assuming an average stream velocity of $0.3 \mathrm{~m} / \mathrm{s}$ ) and a water depth of $25 \mathrm{~cm}$ (the depth of the sensors) indicate that the maximum expected temperature increase would only be $0.03^{\circ} \mathrm{C}$, a value that is nearly an order of magnitude smaller than the accuracy of the employed sensors. Even if the sun were at its zenith in late summer, there were no clouds, and the stream section were totally devoid of canopy cover, it would not be possible for solar radiation (the dominant term in the energy balance for an unshaded stream) to sufficiently increase water temperature so that the downstream sensors could detect a change. Thus, the field experiment presented by Larson et al. (2002) and the tabular data presented in their Table 2 have no relevance regarding the issue of whether unshaded vs. shaded water can warm over this short reach. The experiment certainly has no relevance to the importance of conduction, which is the focus of their mathematical development (e.g., see their section on "The Effect of Water Flow on Temperature Profiles" and Appendix A).

\section{(5) Vegetation shade and water tem- perature}

In their abstract, Larson et al. (2002) conclude that the "temperature data taken from a stream channel are used to show that the water flowing in the channel is essentially unaffected by the patterns of vegetation shade on the surface of the channel." Because no measured change in temperature occurred in their experiment, Larson et al. (2002) conclude that vegeta- tion shade has no role in affecting stream temperatures. As indicated in the previous discussion, the experiment was apparently designed, intentionally or unintentionally, so that it was not possible for any change to be measured. Had a longer reach been studied, they would have come to the opposite conclusion.

The conclusion that shade from riparian vegetation does not influence stream temperature is contrary to an abundant body of stream temperature research (e.g., see Beschta et al. 1987, Sullivan and Adams 1990). A wide range of studies have consistently shown, by both field experiments and energy balance modeling, that reductions of shading vegetation along a channel result in increased summertime maximum temperatures during clear-sky conditions. Since energy losses from steams are often of a smaller magnitude, it would appear that the best management strategy to minimixe the potential for high stream temperatures would be to maintain fully functional riparian plant communities.

Two experiments conducted by researchers at Oregon State University specifically addressed the role of shade and stream temperature. One of these involved the use of a shaded and unshaded tank whereby Moore et al. (1999) concluded that "shade is a very important factor in influencing the rate of heating and cooling of water bodies". Shaded tanks had lower maximum and minimum temperatures, with experimental location and air temperature having no significant influence on the rates of heating and cooling. The second study involved the application of shade treatments to an irrigation channel; the channel was chosen to provide the researchers with control over flow, water column depths, and to minimize potential groundwater inputs. From this second study, Peterson et al. (1999) concluded that "results substantiate the hypothesis that stream shade can be an important factor in decreasing water heating".

The erroneous conclusion of Larson et al. (2002) regarding the effects of shade is an extremely important concern. If such a conclusion were accepted by rangeland professionals, it would give pseudo-credibility to assertions that management practices which continue to maintain relatively low levels of riparian vegetation have little effect on stream temperature. We would suggest that the recovery of degraded riparian plant communities (i.e., a recovery of shade and the other important ecological functions associated with healthy streamside vegetation) is a major ecological and environmental concern along 
many rangeland streams throughout the American West. This is particularly the case where high stream temperatures threaten native salmonids or where stream temperatures are out of compliance with water quality standards. The conclusions by Larson et al. (2002) appear to represent a major obstruction to the proper management of rangeland riparian systems.

\section{Final comments}

Larson et al. (2002) focus on a small portion of a single thermal image along the edge of a stream in a draft agency report. From this, they make sweeping generalizations about the inaccuracies of FLIR methodology and conclude that thermal remote sensing is inappropriate for obtaining stream temperature measurements for scientific or management purposes. Such conclusions are very disconcerting. In our review of the literature on thermal remote sensing, we find that the body of published research would disagree with their conclusions.

Larson et al. (2002) used thermodynamic principles to indicate that conduction is likely to be a relatively small portion of a stream's energy balance. We agree that bed conduction is an inefficient energy transfer process and is often of minor significance with regard to stream temperatures. However, in assessing conduction alone they ignore other more important processes that determine temperature patterns along a stream reach. Had Larson et al. (2002) considered a simple energy balance that included the other major energy sources and sinks, their conclusions would have been much different.

The field experiment that Larson et al. (2002) present is inconsequential for assessing the role of shade on stream temperatures. In spite of unconvincing results, they conclude that stream temperature is essentially unaffected by shade. The level of rigor and logic associated with this experiment is disheartening.

Larson et al. (2002) developed their controversial conclusions with little reference to the current literature. For example, they provide only 4 citations from which a reader might evaluate the status of the science -2 are introductory physics texts, and the other 2 are reports by the ODEQ that address basin-wide stream temperatures. With regard to the ODEQ reports, we suggest that Larson et al. (2002) grossly misinterpreted how that agency uses FLIR data. Furthermore, they have chosen to ignore a rich body of published research and energy balance models that would have provided an important guide for assessing the influences of riparian shade and stream temperature. Had the authors sampled this literature, they would have found that it did not support their conclusions.

In recent years, Larson et al. (2002) have produced other reports and articles on stream temperature and have played active roles in criticizing the need for stream temperature management along aridland streams in Oregon and elsewhere in the Pacific Northwest. While the authors obviously have a right to express their views on streamside management and stream temperatures, we urge readers to carefully assess and evaluate the science presented in Larson et al. (2002).

\section{Literature Cited}

Atwell, B.H., R.B. McDonald, and L.A. Bartolucci. 1971. Thermal mapping of streams from airborne radiometric scanning. Water Resour. Bull. 7:228-243.

Belknap, W. and R. J. Naiman. 1998. A GIS and TIR procedure to detect and map wallbase channels in western Washington. J. Environ. Manage. 52:147-160.

Beschta, R.L. 1997. Riparian shade and stream temperature: an alternative perspective. Rangelands 19(2):25-28.

Beschta, R.L. and J. Weatherred. 1984. TEMP-84. A computer model for predicting stream temperatures resulting from the management of streamside vegetation. USDA Forest Service, Watershed Systems Development Group, WSDG-AD-00009. Ft. Collins, Colo.

Beschta, R.L., R.E. Bilby, G.W. Brown, L.B. Holtby, and T.D. Hofstra. 1987. Stream temperature and aquatic habitat: fisheries and forestry interactions. Pp. 191-232. In: E.O. Salo and T.W. Cundy (eds). Streamside Management: Forestry and Fishery Interactions. Univ. Wash., Inst. For. Resour., Cont. No. 57. Seattle, Wash.

Faux, R.N., H. Lachowsky, P. Maus, C.E. Torgersen, and M.S. Boyd. 2001. New approaches for monitoring stream temperature: Airborne thermal infrared remote sensing. Remote Sensing Applications Laboratory, USDA Forest Service. Salt Lake City, Utah.

Kay, J., R.N. Handcock, A. Gillespie, C. Konrad, S. Burges, N. Naveh, and D. Booth. 2001. Stream-temperature estimation from thermal infrared images. Internat. Geoscience and Remote Sensing Symp. 1:112-114.

Larson, S.L., L.L. Larson, and P.A. Larson. 2002. Perspectives on water flow and the interpretation of FLIR images. J. Range Manage. 55:106-111.

Lillesand, T. M. and R. W. Kiefer. 1994. Remote sensing and image interpretation. Wiley and Sons, New York.
McCullough, D., S. Spalding, D. Sturdevant, and M. Hicks. 2001. Summary of technical literature examining the physiological effects of temperature on salmonids. US Environ. Protection Agency, Issue Paper 5, EPA-910D-01-005. $113 \mathrm{pp}$.

Moore, J.A., J.R. Minor, and R. Bower. 1999. The effect of shade on water: a tub study. Pp. 185-199. In: W.C. Krueger, T.K. Stringham, and C.E. Kelley. Environmental and Management Impacts on Stream Temperature. Final Report, Dept. of Rangeland Resour., Oregon State Univ. Corvallis, Ore.

Norton, D.J., M.A. Flood, B.A. McIntosh, N.J. Poage, P.J. LaPlaca, J.P. Craig, R.S. Karalus, J.R. Sedell, C.E. Torgersen, Y.D. Chen, S.C. McCutcheon, V. Duong, H. Puffenberger, J. Moeller, V. Kelly, E. Porter, and L. Shoemaker. 1996. Modeling, monitoring and restoring water quality and habitat in Pacific Northwestern watersheds. Project Report, U.S. Environ. Protection Agency. Washington, D.C.

Peterson, B., T. Stringham, and W. Krueger. 1999. The impact of shade on the temperature of running water. Pp. 176-184. In: W.C. Krueger, T.K. Stringham, and C.E. Kelley. Environmental and Management Impacts on Stream Temperature. Final Report, Dept. of Rangeland Resour., Oregon State Univ. Corvallis, Ore.

Poole, G.C. and C.H. Berman. 2001. An ecological perspective on in-stream temperature: Natural heat dynamics and mechanisms of human-caused thermal degradation. Environ. Manage. 27:787-802.

Sellers, W.D. 1969. Physical climatology. Univ. of Chicago Press. Chicago, Ill. 272 pp.

Sullivan, K. and T.A. Adams. 1990. The physics of stream heating: an analysis of temperature patterns in stream environments based on physical properties and stream data. Weyerhaeuser Tech. Report, 044-5002.90/2, Technology Center. Tacoma, Wash. 129 pp.

Torgersen, C.E., D.M. Price, H.W. Li, and B.A. McIntosh. 1999. Multiscale thermal refugia and stream habitat associations of chinook salmon in northeastern Oregon Ecol. Appl. 9:301-319.

Torgersen, C.E., R.N. Faux, B.A. McIntosh, N.J. Poage, and D.J. Norton. 2001. Airborne thermal remote sensing for water temperature assessment in rivers and streams. Remote Sensing of Environ. 76:386-398. 